\title{
ISLAM DI AFRIKA UTARA BAGIAN BARAT (AL MURABITUN)
}

\author{
Rina Dewi Ayuarini \\ Universitas IImu Al-Quran Wonosobo \\ TIp. +628121552550 e-mail: bundanina@yahoo.co.id
}

\section{Abstract}

The objective of this study is to describe the formation process of al Murabitun dynasty, and also discussing on the prosperity, the decrease, and the destruction of al Murabitun dynasty. Al Murabitun dynasty was the unique dynasty as it was built based on the spirit of religiousity. And also the existance of the dynasty has been wellknown as it had wide area covering all of Africa and Spain. At the following time, the dynasty experienced the decrease after it had been lead by the third last king, until finally it faced the destruction period. The main cause of the down of the dynasty was a movement which was known as al-Muzwahhidun dynasty. The destruction the dynasty caused by its power which was not in line with the attitude of tolerance of the society. The exploration on the spam of the dynasty will, then, strengthen our point of view on the ups and downs side dynasties in Islam as this is meaningful resource for Islamic scholars.

Key words: Al Murabitun dynasty, prosperity, and decrease

\section{Pendahuluan}

Kekuasaan Islam sudah sampai Afrika sejak masa pemerintahan Abd al Malik dari dinasti Umayyah. Keberadaan Islam di 
Afrika rnengalami pasang surut dan akhirnya dapat dikuasai kembali di bawah komando Musa ibn Nusair. Penaklukan yang dilakukannya, ditandai dengan kekalahan Barbar. Barbar mempunyai banyak suku, diantaranya suku Lamtunah. Suku tersebutoleh Tariq ditempatkan di Tanjah. Agama yang mereka anut sebelumnya adalah Majusi dan setelah Islam menguasai, mereka masuk Islam. Suku tersebut suka menyendiri dan menjauhkan diri dari keramaian kota dan mereka kebanyakan bermukim di padang pasir di Maghrib al Aqsa. Suku ini kemudian lebih terkenal dengan sebutan al Murabitun.

Dinasti al Murabitun dalam perjalanannya merupakan dinasti yang unik. Dinasti tersebut didirikan atassemangat keagamaan dan keberadaan dinasti tersebut diakui karena mempunyai wilayah yang luas meliputi seluruh Afrika dan Spanyol.

Kajian ini dimaksudkan untuk mendiskripsikan dinasti al Murabitun, terutama membahas pembentukan, kejayaan, kemunduran dan kehancuran. Kajian seperti ini semakin penting, karena untuk menelusuri keberadaan Islam pada saat itu dan sekaligus sebagai khazanah keilmuan.

\section{Nama, Asal-Usul dan Pembentukan}

Al Murabitun disebut juga dengan al Murawiyah, al Mutalassimah, atau menurut orang Eropa biasa disebut al Moravids, yakni merupakan sebuah dinasti yang dibangun oleh kelompok sukusuku yang menyebar luas di daerah Afrika pada abadkelima Hijriyah atau abad kesebelas Masehi, dan kekuasaannya meliputi seluruh wilayah Afrika dan sampai juga di Spanyol (Hasan, 1993: 50).

Terdapat beberapa versi penamaan dinasti tersebut dengan sebutan al Murabitun. Pertama, diambil dari kata ribat (biara), yang berarti orang yang hidup di dalam biara (Ali, 1969: 39). Dikatakan demikian karena pendiri dinasti ini, Abdullah ibn Yasin, menumpahkan segala kehidupannya untuk agama denganjalan memahami al Quran dan menegakkan Islam. Kedua, sebagaimana diungkap- 
kan oleh Ibnu Idari, penamaan dinasti ini dinisbatkan dengan pertempuran suku Lamtunah Sanhaja. Pada peristiwa tersebut, Abdullah ibn Yasin menyebut kelompok dirinya dengan sebutan al Murabitun dikarenakan kehebatan, kesabaran dan kekuatannya dalam persaudaraan (Humam, 1989: 298). Ketiga, sebagaimana diungkapkan oleh Ibnu Kasir, bahwa al Murabitun berhubungan dengan Abdullah Ibnu Yasin dalam mengangkat Abu Bakr ibn Umar sebagai pimpinan Lamtunah menjadi Amir al Muslimin karena kebaikan Islam dan kaumnya dalam berjihad di jalan Allah (Hassan, 1967: 285).

Ketiga versi di atas pada dasarnya berasal dari kata yang sama, yaitu ribat. Sebelum popular digunakan oleh suku Lamtunah, al Murabitun berarti orang yang taqwa, mujahid di jalan Allah, penganjur agama, yang dilakukan oleh orang-orang yang ikhlas dalam menjalankan agama (Hassan, 1967: 285). Kata ribat juga dapat ditemukan dalam al Quran surat al Anfal (8) ayat 60. Dalam konteks ayat tersebut kata ribat dikaitkan terhadap orang muslim yang berjihad di jalan Allah untuk melakukan dakwah Islam. Kata ribat juga mempunyai arti khusus yang berkembang di Afrika Utara. Arti tersebut dikembangkan oleh madzhab Maliki dalam mengembangkan ajarannya di Masjid Qairawan. Seruan yang dilakukan ialah agar senantiasa bersikap zuhud dan beribadah. Dari seruan tersebut, timbul usaha untuk menjauhkan diri dari kehidupan duniawi dan pergi ke ribat untuk mempelajari ilmu-ilmu agama.

Untuk menelaah lebih jauh atas dinasti ini, setidaknya harus ditelusuri masa-masa yang dilewatinya, baik masa sebelum sebagai dinasti, masa sebagai kekuasaan keagamaan dan masa sebagai dinasti.

Perjalanan al Murabitun sudah dimulai sejak tahun $440 \mathrm{H}$., ketika Yahya Ibnu Ibrahim, seorang kepala keagamaan suku Sanhaja yang memiliki semangat keagamaan yang kuat, berusaha mengamalkan ajaran agama, melaksanakan perjalanan ibadah haji dan sekaligus berziarah ke makam Nabi Muhammad SAW. Ketika ia pulang ke tanah airnya, dalam perjalanannya ia melewati kota 
Qairawan (Tunisia), dan bertemu dengan Syekh Abu Amran al Fasi, seorang ulama bermadzhab Maliki (Syalabi, 1979: 144-145). la amat tertarik dengan halaqah yang dipimpin oleh syekh tersebut. Sebagai langkah awal, syekh berdialog dengannya, lalu ia terkejut karena ternyata ia tidak memiliki keahlian yang baik dalam keagamaan padahal ia adalah pemimpin agama. Kemudian, syekh bertanya: "Mengapa hal itu bisa terjadi?", ia menjawab di daerahnya tidak ada seorangpun yang mengajarkan ilmu keagamaan, alhasil orang-orang di daerahnya bodoh dan kemudian ia meminta agar dikirim da'i untuk mengajarkan agama. Atas permintaan tersebut akhirnya syekh mengirimkan seorang guru untuk mengajarkan misi keagamaan. Misi tersebut ia percayakan kepada Abdullah Ibnu yasin.

Dalam usaha penyebaran agama Islam, Yahya Ibnu Ibrahim wafat dan dilanjutkan oleh Abdullah Ibnu Yasin. Perjuangan selanjutnya dibantu oleh pemimpin kabilah Lamtunah, Yahya Ibnu 'Umar dan Abu Bakr Ibnu 'Umar dengan membangun tempat peribadatan ribat di Niger (Sinegal). Dari tempat inilah kemudian oleh para penghuninya disebut dengan al Murabitun. Perkumpulan ini berkembang dengan pesatnya dan tercatat dalam waktu yang singkat pengikutnya berjumlah 1000 orang (Syalabi, 1979: 144-145). Di antara pengikutnya ialah sejumlah prajurit-prajurit dari suku Jadalah, Musifah, Lamtunah dan warga sekirtarnya (Brockelman. 1968: 318).

Perkumpulan ini diorganisir dengan baik oleh Abdullah Ibnu Yasin yang memegang urusan politik dan administrasi keuangan, sedangkan Yahya Ibnu Umar diberi jabatan sebagai kepala militer. Usiha maju yang dilakukan ini membawa dampak yang prestisius dengan banyaknya perluasan wilayah yang dilakukan. Tercatat dapat menguasai sampai Wadi Dari'ah dan menaklukkan kerajaan Sijilmasat, yang dikuasai oleh Wanuddin al Marghani pada tahun $447 \mathrm{H} . / 1055 \mathrm{M}$ (Watt, 1992: 96). Usaha-usaha yang dilakukan tersebut tidak terlepas pula dari bantuan Yusuf Ibnu Tasyfin. Penaklukkan yang dilakukan selanjutnya ialah di daerah suku Barghawata pada tahun $451 \mathrm{H}$. yang dianggap memiliki paham bid'ah. Dalam peperangan ini Abdullah bni Yasin mingrgl duma dan sempat 
meninggalkan pesan agar senantiasa melanjutkan misi yang diembannya terdahulu.

Semenjak wafatnya Abdullah Ibnu Yasin, Abu Bakr Ibnu 'Umar memegang pucuk pimpinan secara penuh dan dari sinilah awal pembentukan dinasti al Murabitun. Pemimpin baru segera mengadakan penaklukkan ke sejumlah tempat dengan pembagian untuk bagian utara dilakukan oleh Yusuf Ibnu Tasyfin dan bagian selatan oleh Abu Bakr Ibnu Umar.

\section{Al Murabitun sebagai Negara}

Di kalangan sejarawan, diungkapkan bahwa awal terbentuknya dinastial Murabitun sebagai dinasti, dimulai sejak berkuasanya Abu Bakr ibn 'Umar. Masa pemerintahan al Murabitun berlangsung selama 90 tahun dan mengalamai pergantian raja sebanyak enam kali, yaitu Abu Bakar al Lamtuni (448-480 H.), Yusuf Ibnu Tasyfin (453 H.), Ali Ibnu Yusuf (500 H.), Tasyfin Ibnu Ali (537 H.), Ibrahim Ibnu Tasyfin $(540 \mathrm{H}$.) dan Ishaq Ibnu Ali (540-541 H.). Di antara keenam raja tersebut yang memegang kendali pemerintahan terlama hanya Yusuf Ibnu Tasyfin dan Ishaq Ibnu Ali. Sedangkan raja sesudahnya hanya berkuasa dalam waktu yang singkat dan mengalami masa kemunduran dan sebagai puncaknya mengalami kehancuran.

Berdirinya dinasti al Murabitun tidak lepas dari faktor-faktor yang melingkupinya. Di antara faktor tersebutialah adanya perebutan kekuasaan antara Ghannah dan Mulassimah yang mengakibatkan adanya resesi ekonomi dan adanya semangat yang membara di kalangan al Murabitun. Sedangkan faktor eksternal ialah adanya keinginan yang membara di antara suku-suku diSahara untuk tetap berada di bawah kekuasaan Khalifah Bani Abbas dan adanya serangan yangyang dilancarkan oleh orang Kristen terhadap daerah Islam.

Dinasti al Murabitun mencapai puncak kejayaan pada masa pemerintahan Yusuf Ibnu Tasyfin, yang bergelar amir al muslimin. 
Peran politiknya didasari atas semangat keagamaan untuk berjihad dalam memberantas kejahatan-kejahatan. Dari semangat ini kemudian ia dapat mencapai puncak kejayaannya, ketika menyerang Spanyol. Pada dasarnya kedatangannya ke Spanyol atas undangan Amir Cordova al Mu'tamid Ibnu Abbas yang merasa terancam kekuasaannya oleh Raja Alfonso VI (Raja Castile dan Leon). Dalam usaha ini, ia dibantu oleh raja-raja kecil yang berada di Andalusia (Muluk al Tawaif) dengan jumlah pasukan sebanyak 20.000 dan menghadapi tentara Alfonso VI sebanyak 60.000. Pertempuran tidak dapat dielakkan dan akhirnya Alfonso kalah pada tahun $479 \mathrm{H}$. (23 Oktober 1086 M.).

Terhadap gelar yang disandangnya Amir al muslimin, pada mulanya dipakai oleh Abdullah Ibnu Yasin. Sedangkan pemakaian atas dirinya dimulai sejak ia dapatmenguasai sebagian besar Maroko, sepanjang Pantai Atlantik dan sebagian besar dari Sahara. Sebutan tersebut tidak lain hanyalah sebagai pemberian hormat terhadap kabilah yang dipersatukan oleh Abdullah Ibnu Yasin. Namun ia menolaknya dengan dasar ia takut kepada Allah karena yang patut mendapat gelar tersebut hanyalah Khalifah Abbasiah, karena ia merupakan keturunan NabiSAW, dan penguasa Makkah dan Madinah sedangkan Yusuf hanyalah pelaku dakwah, untuk itu ia menerima sebutan amir al muslimin (prince of the muslim's). Namun ada yang mengatakan lain terhadap adanya gelar tersebut, didapatkan atas pemberian khalifah Abbasiah

Keadaan perekonomian pada waktu itu sangat makmur, dimana penghasilan negara sebanyak 120.000 pounds emas. Di samping itu, ada sejumlah penghapusan terhadap pajak yang tidak ada sandaran hukumnya di dalam al Quran sehingga rakyat dapat menikmati dalam kedamaian dan keamanan. Sebaliknya dalam bidang keilmuan tidak berkembang dengan pesat namun justru terjadi perkembangan pada seni dan dekorasi (Imamuddin, 1965: 263).

Tahun 500 H./ 1105 M. Yusuf Ibnu Tasyfin meninggal dunia dan kedudukannya digantikan oleh All ibn Yusuf. Ia menjabat 
dalam usia 29 tahun dan mewarisi kekuasaan yang besar. Karirnya dimulai dengan penaklukkan keSaragosa. Atas bantuan penduduk setempat ia dapat mengalahkan raja Alfonso VI. Dalam pertempuran tersebut raja dan anaknya tewas. Atas bantuan panglima militer Sir Ibnu Abu Bakar, ia dapat menaklukkan Lisbon (Portugal), Badajos, Oporto, Evora, dan Santarem. Namun keberhasilan ini tidak berlangsung lama setelah kematian Tamim. Daerah tersebut dikuasai lagi oleh Raja Alfonso I dengan bantuan Perancis (Imamuddin, 1965:265). Setelah itu Ali kembali ke Afirika dan meninggal pada tahun $1145 \mathrm{M}$.

\section{Kemunduran dan Kehancuran}

Dinasti al Murabitun mengalami kemunduran setelah dipegang oleh tiga raja terakhir dan akhirnya mengalami kehancuran. Adapun penyebab kemunduran dinasti ini adalah sebagai berikut:

1. Adanya perubahan sikap dalam berdakwah. Fenomena ini dapat dilihat ketika menguasai Andalusia selama 20 tahun, Yusuf ibn Tasyfin, lebih suka mabuk, memuaskan hawa nafsunya dan bergelimang kemewahan. Para fuqaha' tidak dapat mengubah kebiasaan ini, sehingga kebobrokan moral semakin melanda dikalangan masyarakat dan penguasa (Syalabi, 1979: 147).

2. Pada masa pemerintahan Ali ibn Yusuf tidak semulus pemerintahan sebelumnya. Ia tidak mampu menutupigerakan-gerakan yang berusaha untuk menerobos pertahanannya di Maghrib dan Andalusia.

3. Fuqaha' ambisius dan suka mengkafirkan orang yang menumpuk harta. Di samping itu ia mengkafirkan orang yang berusaha untuk mengkokohkan prinsip aqidah dengan mengembalikan kepada akal. Di antara yang dikafirkan ialah al Ghazali dan menfatwakan agar membakar karya-karyanya (Brockelman, 1968: 322). 
Sampailah waktu yang menentukan, dinastial Murabitun tumbang oleh suatu gerakan, dan akhirnya menjadi sebuah dinasti dengan nama al Muwahhidun. Dengan kehadiran penguasa baru tersebut maka berakhirlah seluruh kejayaan dinasti al Murabitun.

\section{Simpulan}

Dari pembahasan di atas maka dapat disimpulkan bahwa gerakan keagamaan dari suku-suku Barbar di Afrika menjadi sebuah dinasti yang mempunyai kekuasaan yangluas. Keperkasaan yang didapatkan dari usaha penaklukkan tidak diimbangi dengan sikap toleran yang ada terhadap masyarakatnya. Akhirnya dinasti ini mengalami masa kehancuran dengan munculnya sebuah gerakan baru yang menentangnya.

\section{Daftar Pustaka}

Ali, Ameer. 1969. The Concise Encyclopaedia of Islam. London: Stacey International.

Bosworth, C.E. 1993. Dinasti-dinasti Islam. Terjemahan oleh Myas Hasan. Bandung: Mizan.

Brockelman, Carl. 1968. Tarikh al-Syu'ub al-Islamiyyah. Bairut: Dar alIlm li al-Malayin.

Hassan, Ibrahim Hassan. 1967. Tarikh al-Islamiy. Kairo: Maktabah alMishriyah.

Imamuddin, S.M. 1965. A Political History of Muslim Spain. Karachi: Najmah Sons.

Syalabi, A. 1979. Mausu'at al-Tarikh al-Islamiy wa al-Hadarat al-Islamiyyah Mesir: Maktabah al-Nahdah al-Mishriyah.

Watt, W. Montgomery.1992. A History of Islamic Spain. Edinburg: At The University. 